\title{
High resolution numerical study of the Algiers 2001 flash flood: sensitivity to the upper-level potential vorticity anomaly
}

\author{
S. Argence ${ }^{1}$, D. Lambert ${ }^{1}$, E. Richard ${ }^{1}$, N. Söhne ${ }^{1}$, J. -P. Chaboureau ${ }^{1}$, F. Crépin ${ }^{2}$, and P. Arbogast ${ }^{3}$ \\ ${ }^{1}$ Laboratoire d'Aérologie, CNRS/UPS, Toulouse, France \\ ${ }^{2}$ Météo France CNRM/GMAP, Toulouse, France \\ ${ }^{3}$ Météo France DPrevi/Labo, Toulouse, France
}

Received: 26 October 2005 - Revised: 23 January 2006 - Accepted: 27 January 2006 - Published: 14 March 2006

\begin{abstract}
From 9 to 11 November 2001, intense cyclogenesis affected the northern coasts of Africa and more particularly the densely populated city of Algiers. During the morning of 10 November, more than $130 \mathrm{~mm}$ of precipitation was recorded at Bouzareah and resulted in mudslides which devastated the Bab-el-Oued district. This disaster caused more than 700 casualties and catastrophic damage. Like many other heavy rainstorms in the western Mediterranean, this event was associated with the presence of an upper-level trough materialized by a deep stratospheric intrusion and characterized by high potential vorticity values. In this study, the impact of this synoptic structure on the localization and intensity of the precipitation which affected Algiers is investigated using a potential vorticity (PV) inversion method coupled for the first time with the French nonhydrostatic MESO-NH model. A set of perturbed synoptic environments was designed by slightly modifying the extent and the intensity of the coherent potential vorticity structures in the operational ARPEGE analysis. It is shown that such modifications may have a strong impact on the fine-scale precipitation forecast in the Algiers region, thereby demonstrating the fundamental role played by the potential vorticity anomaly during this exceptional meteorological event.
\end{abstract}

\section{Introduction and purpose of the study}

The Mediterranean climate, usually pleasant, with sunshine and its fine weather, can become very hazardous: the coastal regions are regularly struck by severe rainstorms often causing catastrophic material damage and sometimes casualties. A characteristic of these heavy rainfall situations, often associated with strong winds, is the role, evident a posteriori, of the synoptic context. Detailed analyses of different rainstorm cases in the Mediterranean region underline the presence of an upper-level trough often associated with

Correspondence to: S. Argence

(sebastien.argence@aero.obs-mip.fr) these storm systems, see for example the extreme flash flood event of September 2002 in the Gard region (France) (Delrieu et al., 2005). This upper-level structure is associated with a stratospheric intrusion in the troposphere and is characterized by high potential vorticity values. Such a meteorological situation occurred during the Algiers severe cyclogenesis of November 2001, resulting in more than 700 casualties, thousands of injuries and millions of euros of damages. In this study, a potential vorticity inversion method has been coupled, for the first time, with the French non-hydrostatic MESO-NH model and has been used to study the impact of the upper-level dynamical structures on the intensity and the distribution of the precipitation on 10 November 2001 in the Algiers region. Section 2 provides a brief description of the meteorological situation. The sensitivity to the model horizontal resolution is studied in Sect. 3 before investigating, in Sect. 4, the role played by the upper-level potential vorticity anomaly. Conclusions and perspectives for future work are given in the final section.

\section{Description of the meteorological situation from 9 to 11 November 2001}

On 9 November, 12:00 UTC, an upper-level trough associated with a deep elongated stratospheric intrusion was present from Scandinavia to the Iberian Peninsula, advecting cold polar air $\left(-22^{\circ} \mathrm{C}\right)$ over the Algerian coasts (Fig. 1a). Due to the presence of the trough, an intense upper-level jet-streak (up to $60 \mathrm{~ms}^{-1}$, not shown) was located over the southern edge of the Atlas mountains. In the low levels, a weak cyclone centred over the golf of Genoa advected cold air over the Mediterranean sea toward the north of Morocco and Algeria, inducing a strong temperature gradient over the northern coasts of Africa (Fig. 1b). Favourable conditions for cyclogenesis development were already present in this synoptic environment of 9 November, these conditions being aggravated in the next few hours of the event. On 10 November, 00:00 UTC, the intruded stratospheric air had moved 
(a)
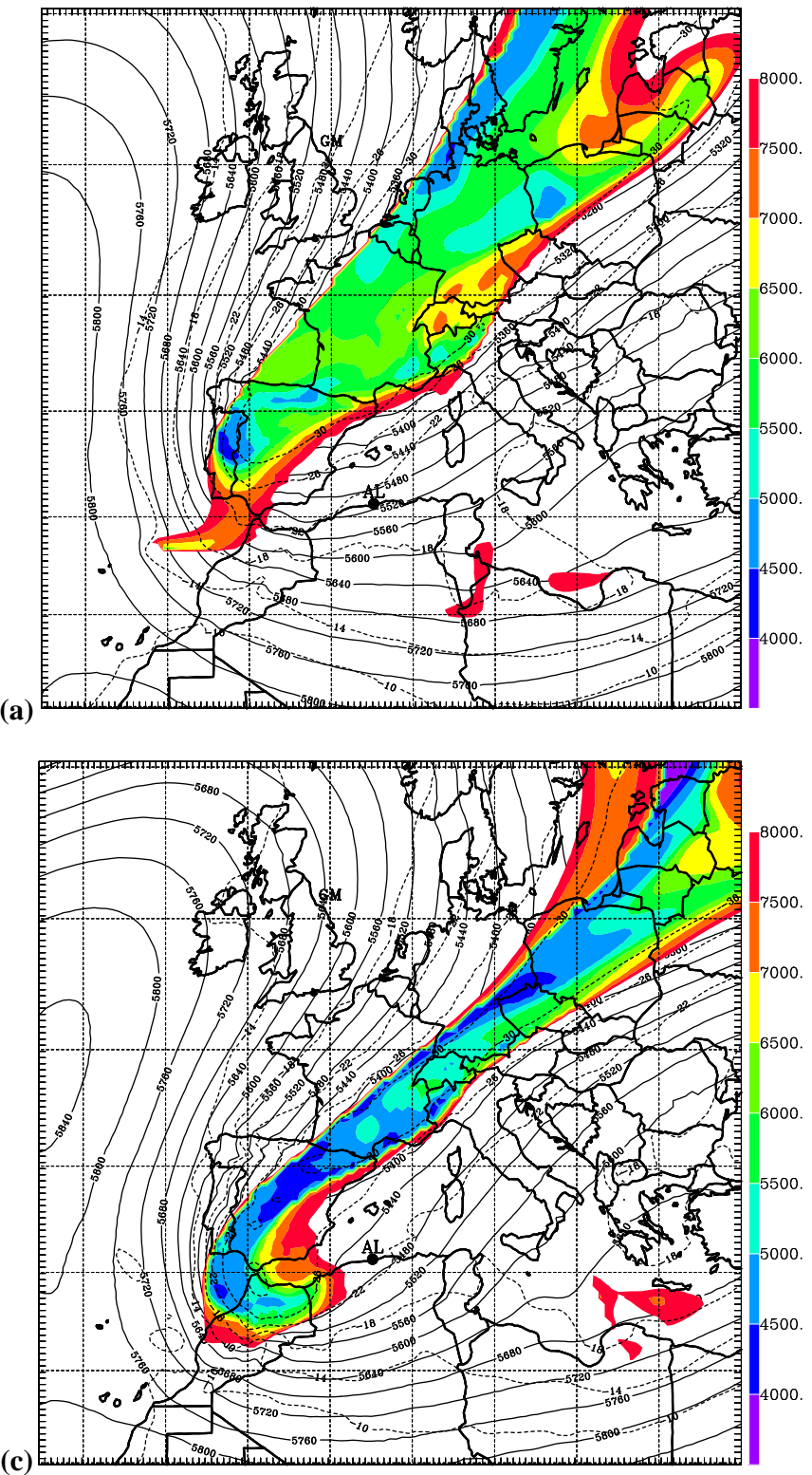

(b)

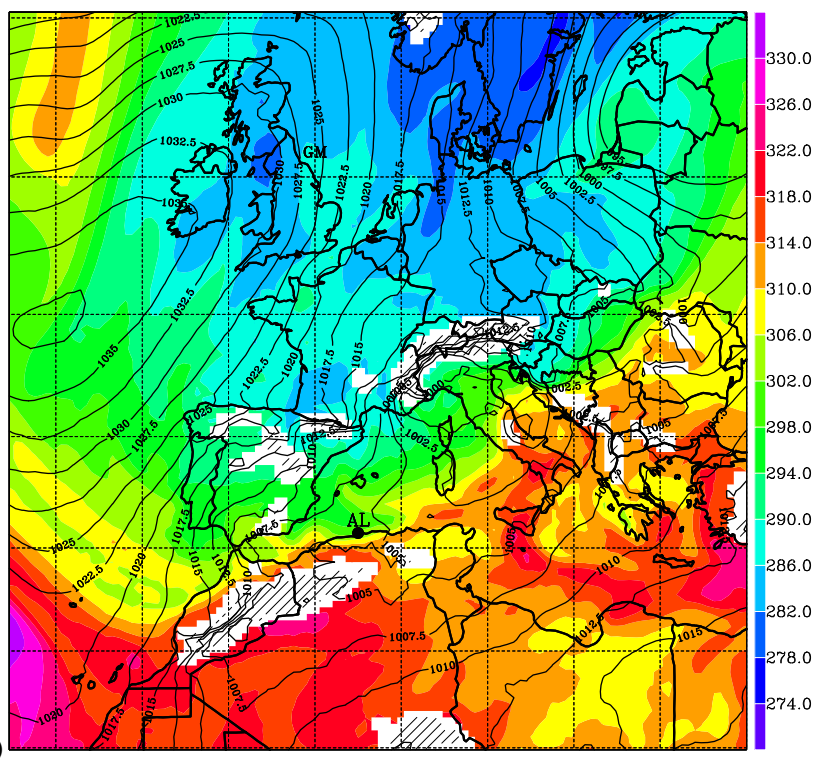

(d)

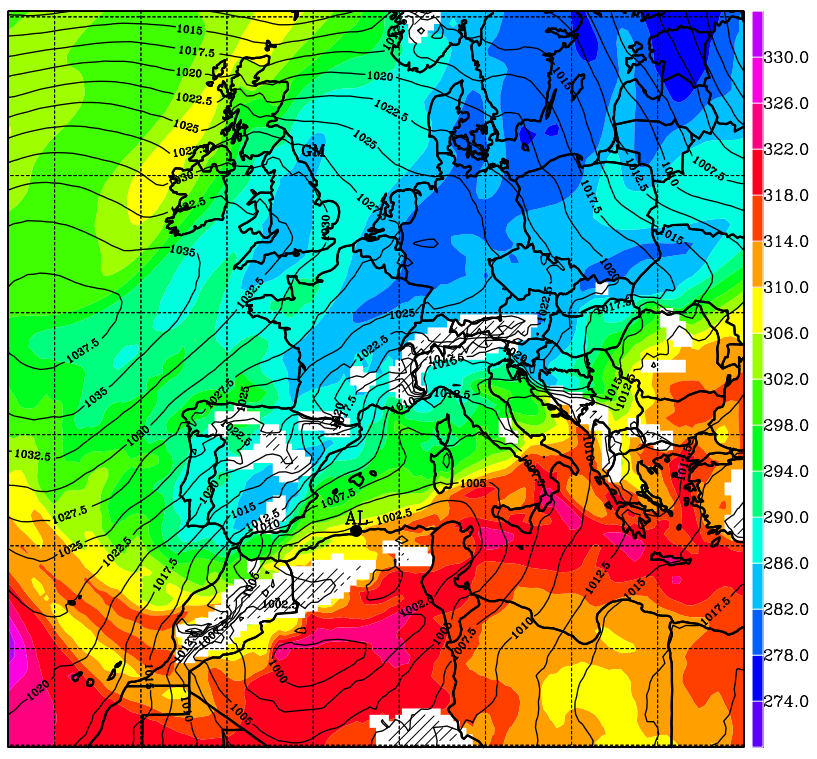

Fig. 1. (a,b) ARPEGE analysis for 9 November 2001 at 12:00 UTC, and (c,d) for 10 November 2001 at 00:00 UTC: (a), (c) $500 \mathrm{hPa}$ geopotential height (solid lines, $\mathrm{m}$ ), $500 \mathrm{hPa}$ temperature (dashed lines, ${ }^{\circ} \mathrm{C}$ ) and topography of the 1.5 pvu surface (colours, $\mathrm{m}$ ); (b), (d) mean sea level pressure (solid lines, $\mathrm{hPa}$ ) and $1000 \mathrm{~m}$ equivalent potential temperature (colours, $\mathrm{K}$ ).

south-eastward, still inducing cold air advection over north Algeria (Fig. 1c), while a surface low (996 hPa) developed over the Saharan Atlas, advecting warm, moist air on to the Algerian coasts (Fig. 1d). In consequence, convection developed over the south-western Mediterranean, resulting in intense precipitation along the Moroccan and Algerian coasts. The heaviest rainfalls were located over Algiers ( $262 \mathrm{~m}$ during the entire storm episode with more than $130 \mathrm{~mm}$ in the morning of 10 November, Fig. 4a) whereas only $41 \mathrm{~mm}$ was recorded at the Dar-el-Bedia station, situated inland, only 15 $\mathrm{km}$ from Algiers. On 11 November, 00:00 UTC, the surface low moved northward inducing a northern flow and strong wind gusts $\left(33 \mathrm{~ms}^{-1}\right)$ on the Algerian coasts and generating waves 6 to $8 \mathrm{~m}$ high. In the next $6 \mathrm{~h}$, the cyclogenesis intensified before reaching the Balearic Islands where damage was also considerable.

\section{Numerical study of the event}

\subsection{Characteristics of the MESO-NH simulations}

Three simulations performed with the French nonhydrostatic mesoscale model MESO-NH (Lafore et al., 1998) are presented in this paper: one with a single domain 
using a $50 \mathrm{~km}$ horizontal mesh size and two with three nested domains with horizontal mesh sizes of 50, 10 and $2 \mathrm{~km}$ resolution. Figure 2 depicts the location of the different model domains. All the simulations started on 10 November, 00:00 UTC, and were integrated for a period of $12 \mathrm{~h}$. They were initialized with either the reference or the modified operational ARPEGE analysis of 10 November, 00:00 UTC. Note that our numerical study does not treat the whole event but only its most critical phase, that is to say 10 November from 06:00 to 12:00 UTC.

\subsection{Sensitivity to the horizontal resolution}

To first evaluate the impact of increasing the model resolution on the rainfall prediction, two experiments were performed, with one domain and three nested domains. In both experiments, initial conditions were obtained from the large scale ARPEGE analysis. It was hypothesized that the high-resolution model might rapidly reproduce the pertinent mesoscale structures by dynamical adaptation to the surface conditions (topography for example) and by a better representation of physical processes (microphysics, turbulence,...). Accumulated rainfalls obtained with the single domain (50 km resolution, parameterized convection) and with the three nested domains ( $2 \mathrm{~km}$ resolution and explicit description of the convection in the innermost one) are compared with the observations of 10 November from 06:00 to 12:00 UTC. With the coarse grid domain only, a heavy rain core of $105 \mathrm{~mm}$ in $6 \mathrm{~h}$ (Fig. 3a) was simulated offshore of Algiers whereas the measured accumulated precipitation for the same period showed a maximum of $132 \mathrm{~mm}$ located over Algiers (Fig. 4b). When three nested domains were used and when convection was explicitly represented in the Algiers region, the localization of the precipitation was not improved. However, its intensity ( $145 \mathrm{~mm}$ in $6 \mathrm{~h}$, Fig. 3b) was closer to the observations.

Figures $3 \mathrm{c}$ and $\mathrm{d}$ show a south-north vertical cross section of the simulated cloud systems in both experiments. Deep clouds (reaching $9 \mathrm{~km}$ ) were produced in both experiments indicating that a significant portion of the precipitation had a large-scale (as opposed to convective) origin. When convection was explicitly resolved, the strengh of the precipitation was reinforced but the cloud system was not drastically modified. Moreover, in both experiments, a southern flow, present over land at almost all levels of the atmosphere, clearly prevented the convective system from reaching the coast. Although an increase of resolution improved the intensity of the accumulated rainfall, it did not yield a better localization of the precipitating area.

\section{Sensitivity of the precipitation to the high-level PV structure}

\subsection{Perturbation of the initial state}

The principle of manipulating the initial state by using a quasi-geostrophic potential vorticity inversion tool

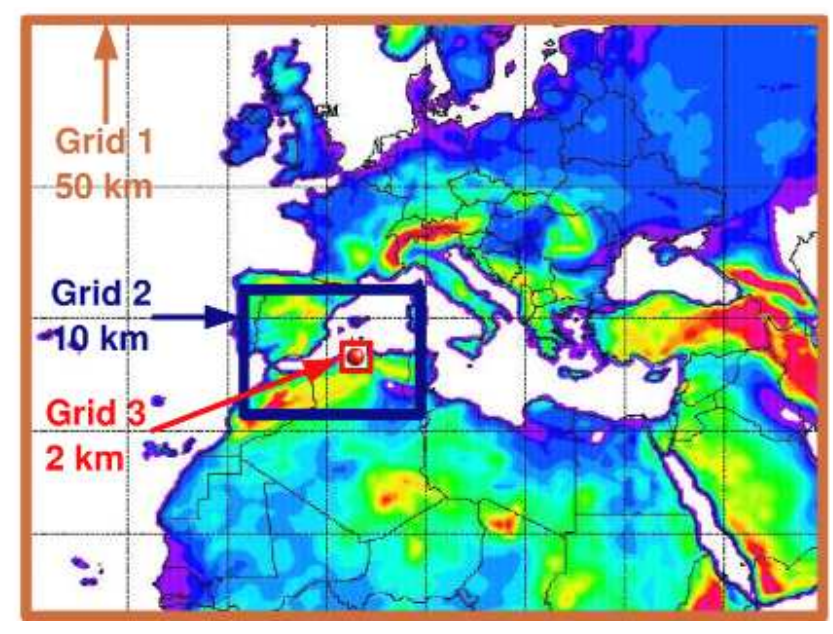

Fig. 2. Simulation domains with topography. The red spot indicates the location of Algiers.

is described in Chaigne and Arbogast (2000). Coherent tropopause disturbances are detected by analysing the topography of the $1.5 \mathrm{pvu}^{1}$ surface, considered to be the dynamical tropopause. This method was applied to the ARPEGE analysis of 10 November 2001 00:00 UTC in order to study the impact of the upper-level PV anomaly on the intensity and the distribution of precipitation. In the sensitivity experiment presented below, the initial state was modified by eroding the potential vorticity anomaly between 500 and $100 \mathrm{hPa}$ on a limited geographic domain (see Figs. 5a, b, c and d). The purpose in this study was not to remove the whole anomaly, but just to slightly modify it in such a way that the amplitude of the modification remained of the same order of magnitude as analysis errors. Then, a second high-resolution MESONH simulation (with the three nested models), initialized with the modified fields, was performed and compared with the reference high resolution simulation.

The perturbation introduced in the initial state was very empirically designed but nevertheless guided from the satellite observation. As the comparison between the model upper-level PV field and the METEOSAT water vapor image did not reveal any obvious mismatch, it was assumed that the location of the dry intrusion (and associated PV anomaly) was reasonably correct in the analysis. However, the comparison between the observed and synthetic (i.e. analysis derived) water vapor images seemed to indicate that, in the analysis, the dry intrusion might be too strong in the area west of the Gibraltar strait. The model PV upper-level field was therefore modified accordingly (but quite subjectively) in this specific area.

\subsection{Results of the sensitivity experiment}

In contrast with the reference simulation, the sensitivity experiment produced a heavy rain core (162 $\mathrm{mm}$ in 6 h, Fig. 6b)

\footnotetext{
${ }^{1}$ Potential Vorticity Unit $\left(1 \mathrm{pvu}=10^{-6} \mathrm{~m}^{2} \mathrm{~s}^{-1} \mathrm{~K} \mathrm{~kg}^{-1}\right)$
} 
(a)
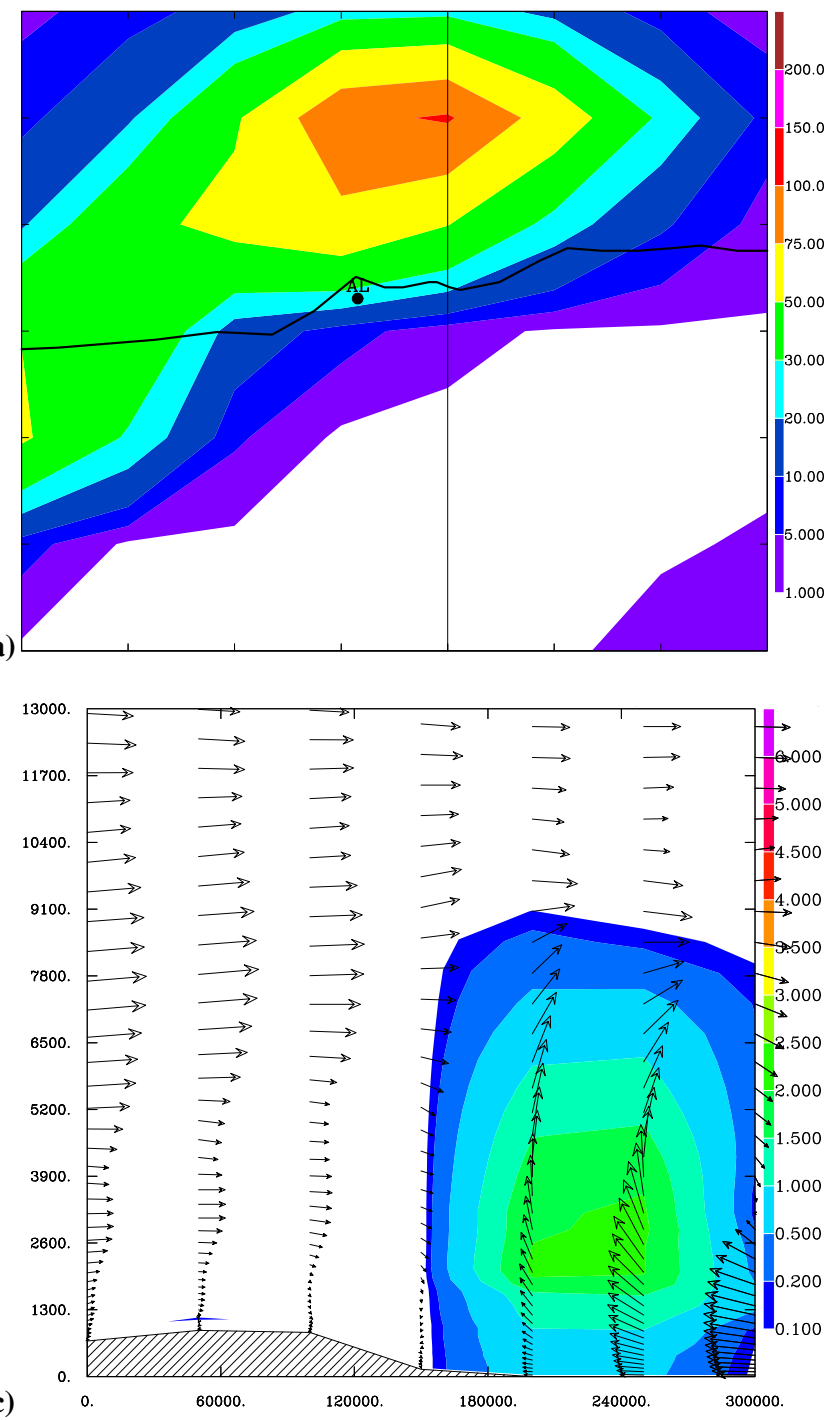

(b)

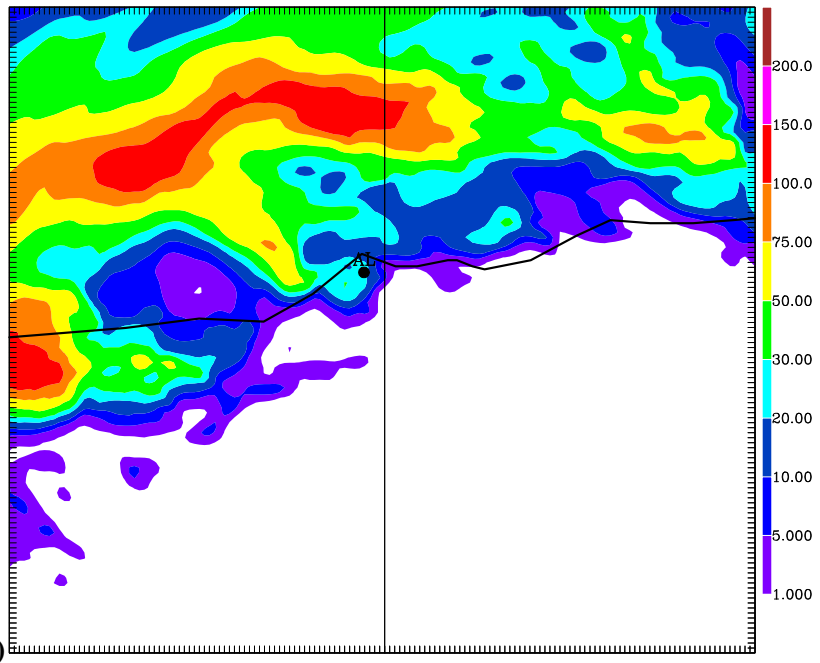

(d)

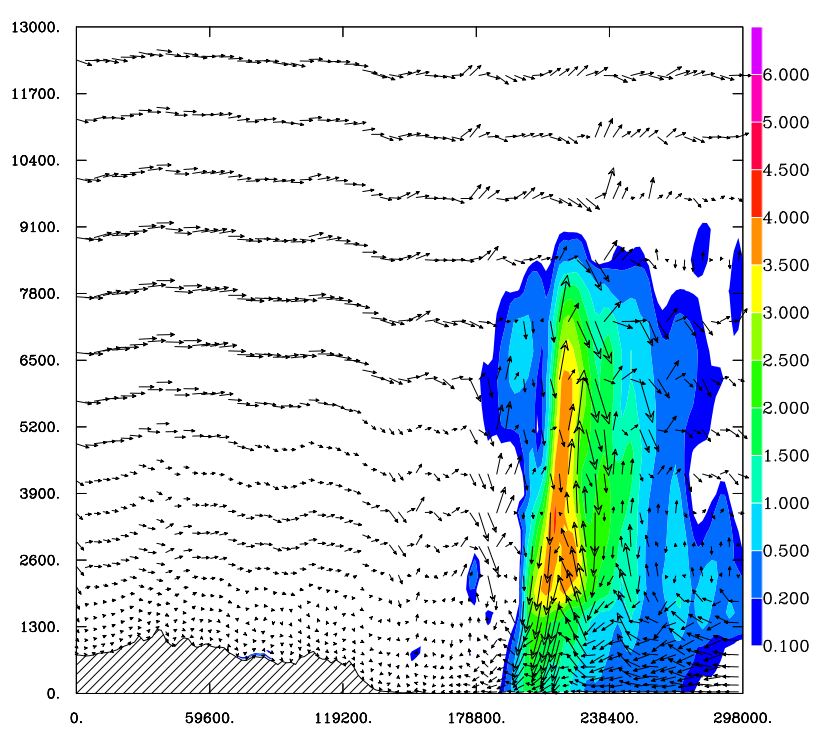

Fig. 3. (a,b) Accumulated simulated rainfall (mm) for 10 November 2001 from 06:00 to 12:00 UTC, and (c,d) simulated south-north vertical cross-section of the total hydrometeor content (colours, $\mathrm{g} / \mathrm{kg}$ ) and wind in the cross-section (black arrows, note the scale is not the same for the two pictures) for 10 November 2001 at 08:00 UTC: (a), (c) coarse resolution simulation (50 km); (b), (d) high resolution simulation $(2 \mathrm{~km})$. The black line on (a) and (b) represents the axis of vertical cross-sections shown in (c) and (d).

(a)

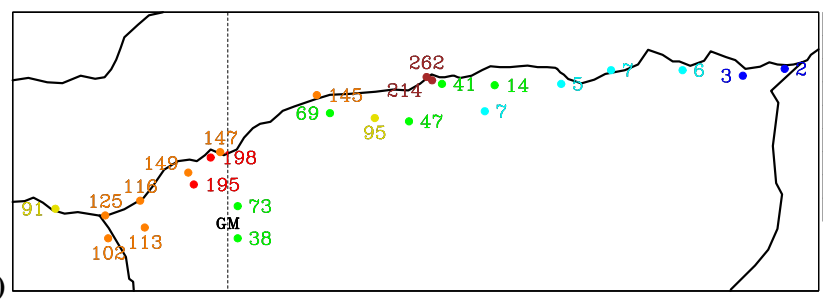

(b)

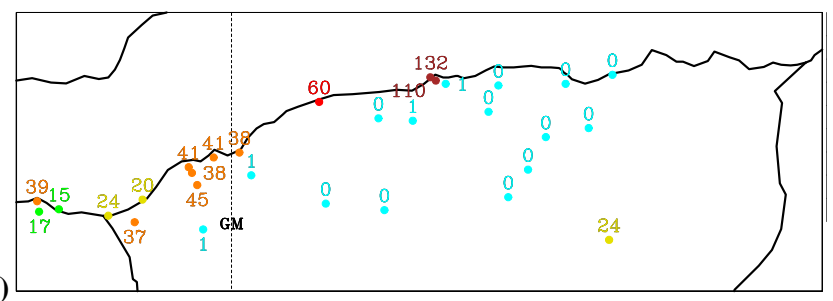

Fig. 4. Accumulated rainfall (mm) recorded in the north of Africa: (a) from the 9 November 06:00 UTC to the 12 November 06:00 UTC; (b) the 10 November 2001 from 06:00 to 12:00 UTC.

still mainly located offshore but now partially affecting the city of Algiers. From a dynamical point of view, an explanation of the differences between reference and sensitivity experiments can be inferred from the low-level flow pattern. In the simulation initialized with the perturbed ARPEGE anal- ysis, low-level convergence occured over the sea in a moist and unstable region located only a few kilometers east of Algiers and pointed towards the high ground surrounding the city (Fig. 6d). In contrast, in the reference experiment, the low-level flow convergence took place much offshore of 
(a)

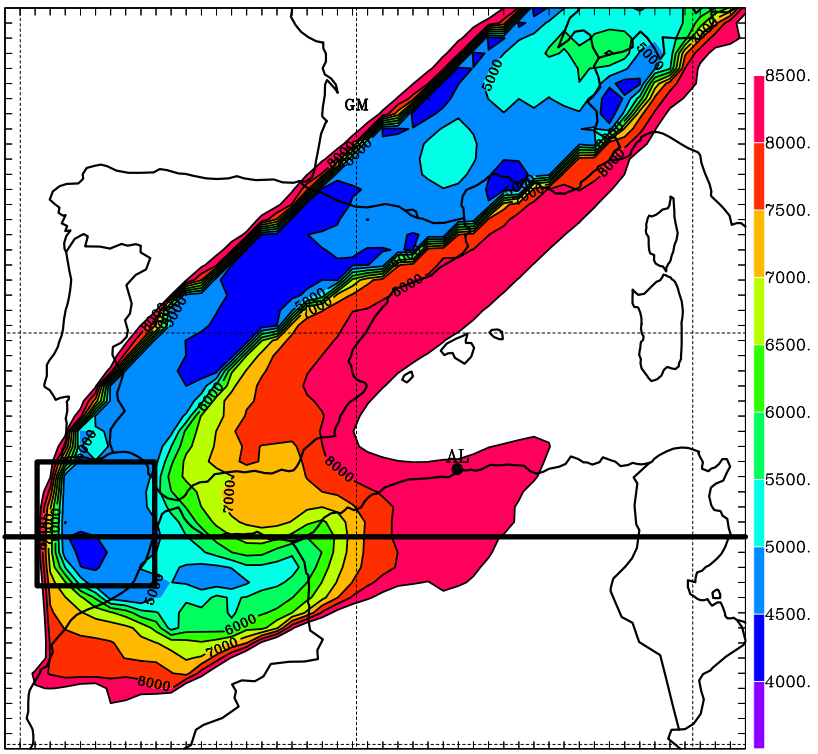

(c)

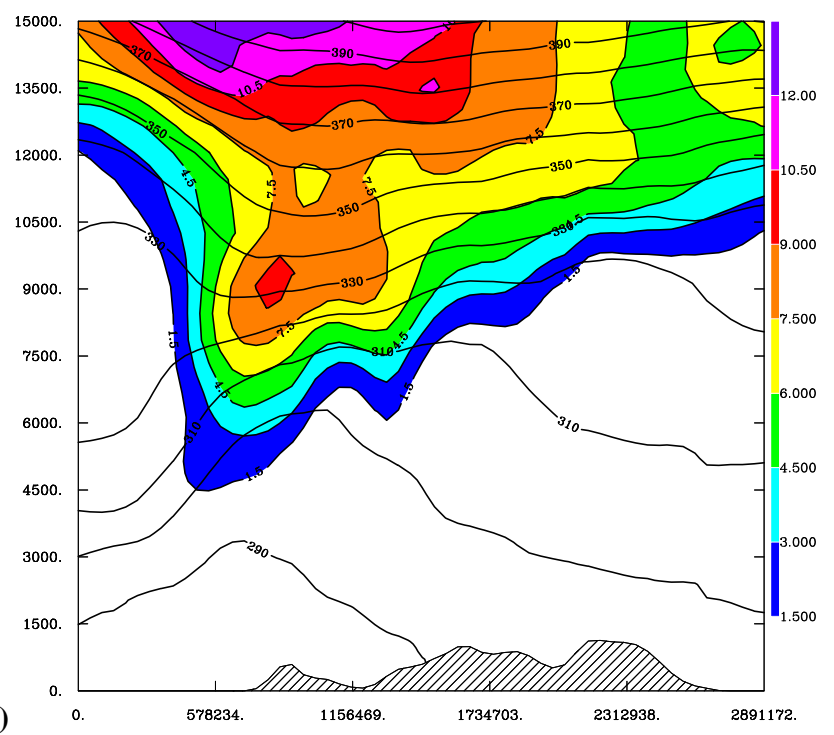

(b)

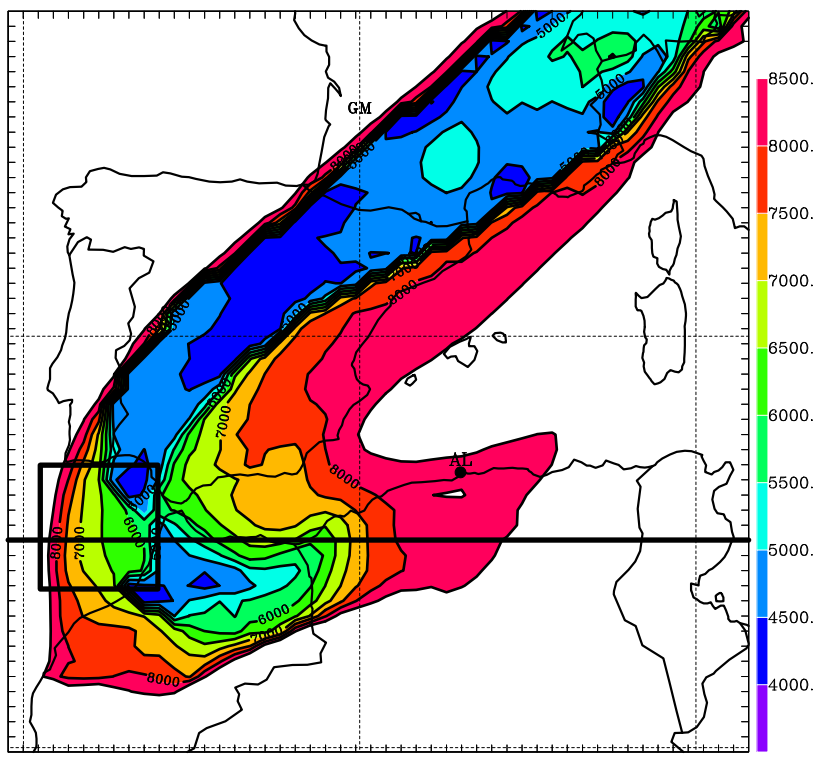

(d)

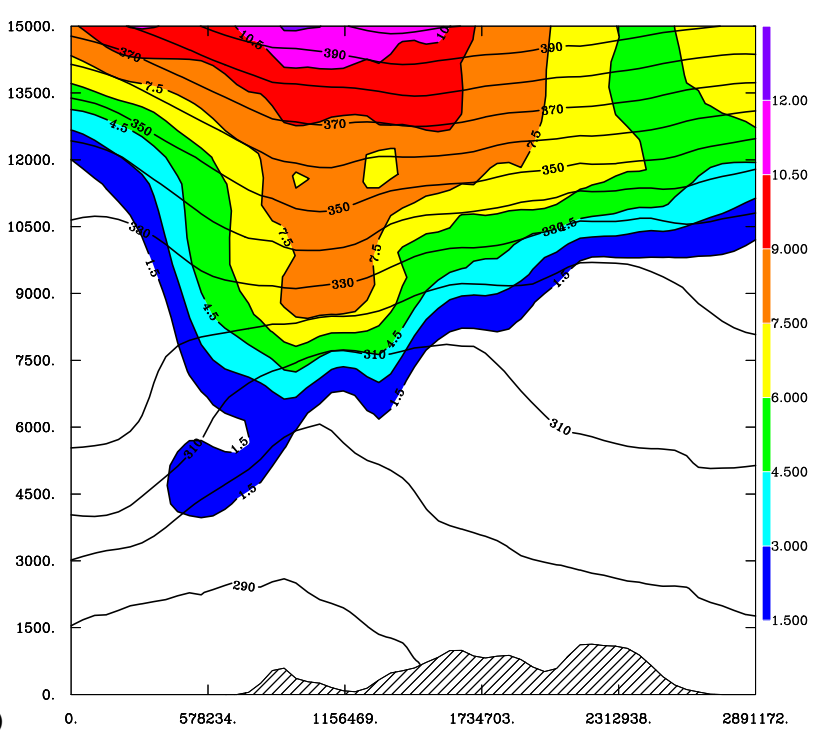

Fig. 5. (a,b) Topography of the 1.5 pvu surface $(\mathrm{m})$, and (c,d) west-east vertical cross-section of potential vorticity (colours, pvu) and potential temperature (solid lines, K) for 10 November 2001 at 00:00 UTC: (a), (c) reference ARPEGE analysis; (b), (d) modified ARPEGE analysis. On (a) and (b), the square represents the inversion area and the black line shows the axis of the vertical cross-sections presented in (c) and (d).

Algiers. Moreover, the low-level wind east of Algiers remained parallel to the coast and did not interact with the topography (Fig. 6c).

These results highlight the role of the upper-level potential vorticity structure (including its subsynoptic details) in determining the precipitation distribution. A weak perturbation of the stratospheric intrusion resulted in a modification of the surface cyclone trajectory leading to a deviation of low-level flow and an increase of the convergence in the vicinity of Algiers. In response to these dynamical modifications, the intensity and the location of the subsequent precipitation were strongly affected.

\section{Conclusions and perspectives}

An entire city devastated by rainfall and the subsequent flooding, hundreds of victims and catastrophic damage, such were the dramatic consequences of the exceptional rainstorm which struck Algiers on 10 November 2001. The extreme character of this event resides in the heavy rainfall recorded during the episode (almost $300 \mathrm{~mm}$ in $24 \mathrm{~h}$ whereas $96 \mathrm{~mm}$ is usually recorded for an entire month during the same period) but also in the stong vulnerability of Algiers city to hydrological risks.

The main objective of this study was to evaluate the impact of the upper-level dynamical structure on the genesis and the distribution of the heavy rainfall which dramatically 
(a)
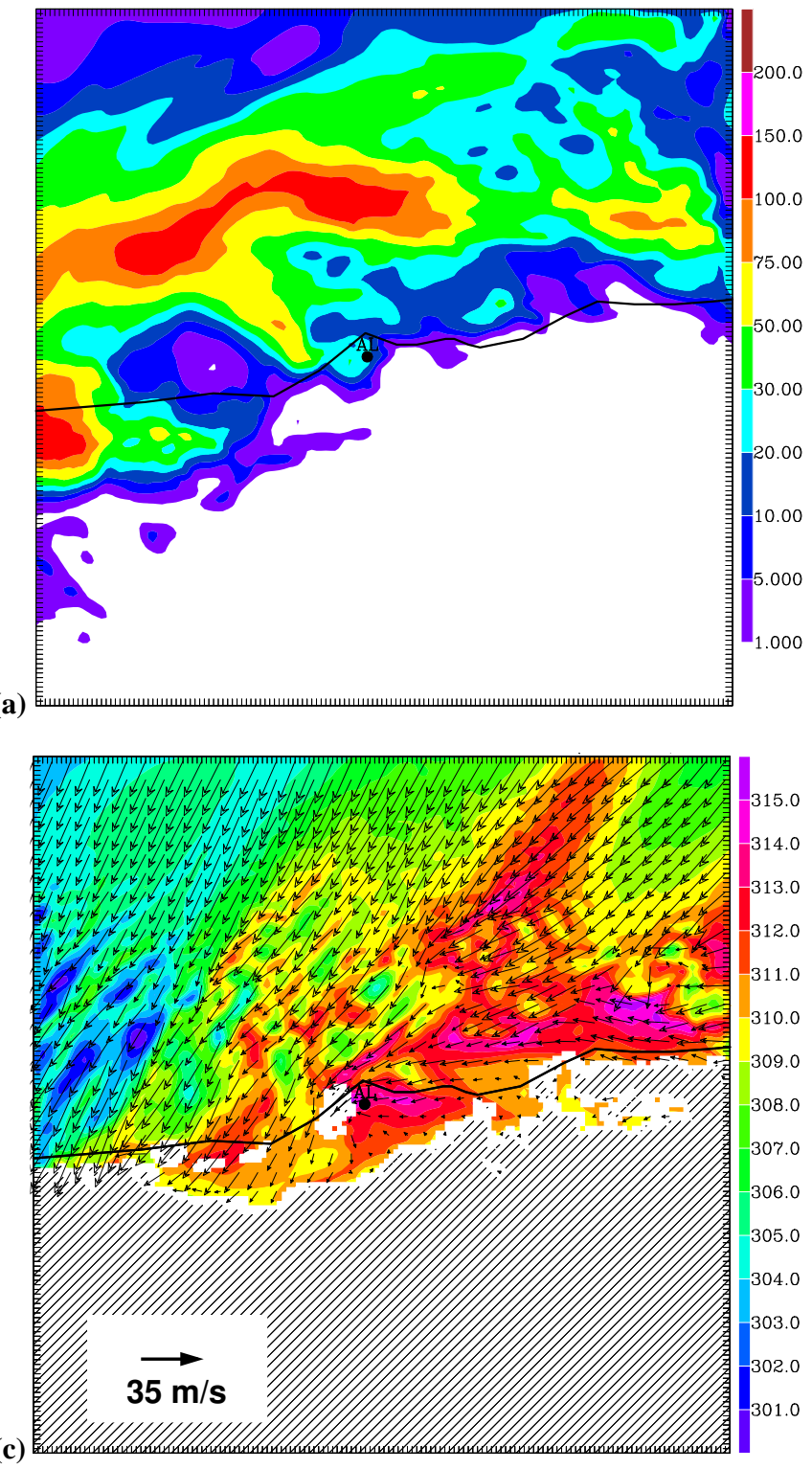

(b)
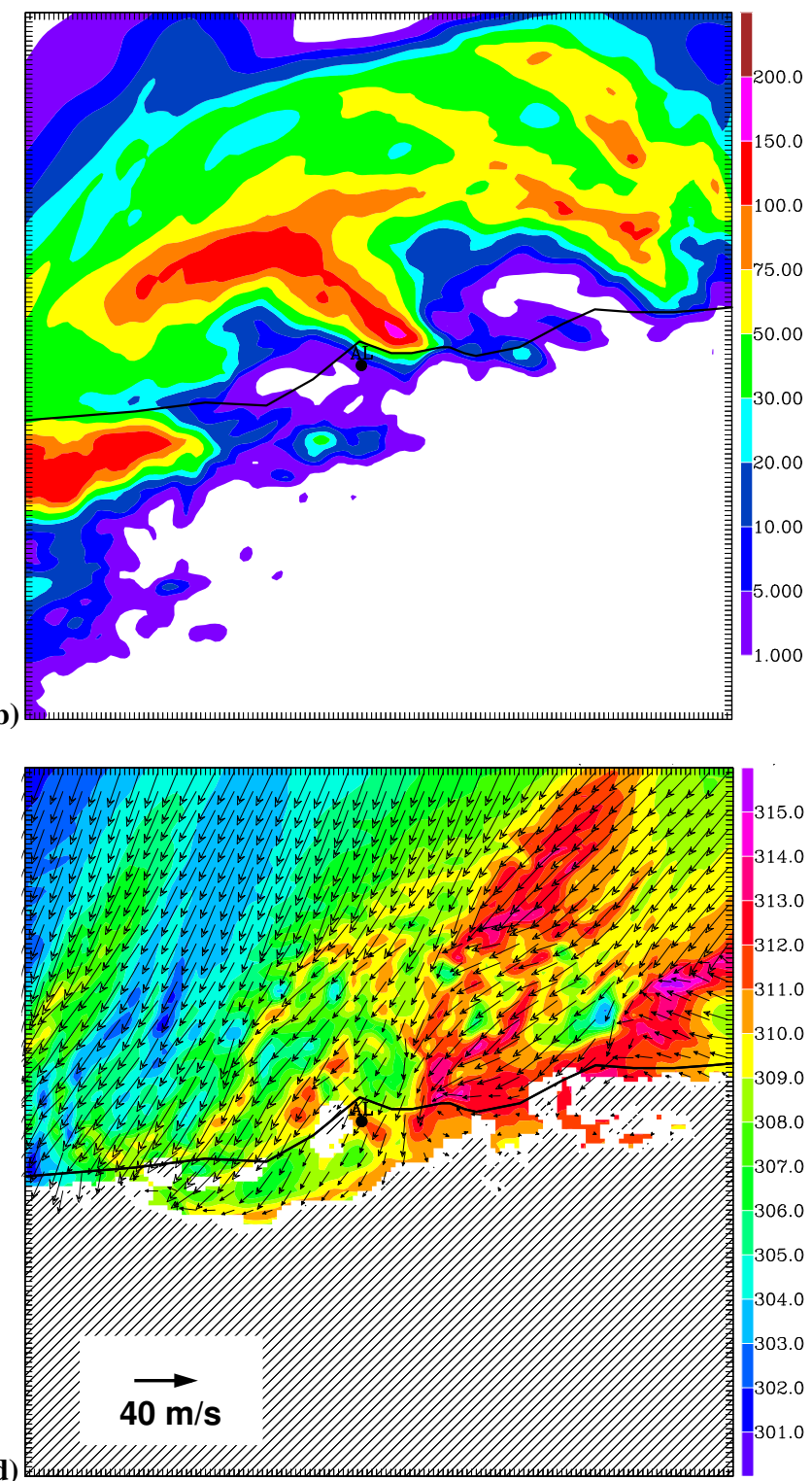

Fig. 6. (a,b) Accumulated simulated rainfalls (mm) for 10 November 2001 from 06:00 to 12:00 UTC on the $2 \mathrm{~km}$ grid model, and (c,d) $200 \mathrm{~m}$ equivalent potential temperature (colours, K) and $200 \mathrm{~m}$ horizontal wind vectors for November 2001 at 08:00 UTC on the $2 \mathrm{~km}$ grid model: (a), (c) reference experiment; (b), (d) sensitivity experiment.

affected Algiers on the morning of 10 November. The numerical experiments performed with MESO-NH have shown that a high-resolution simulation in which convection is explicitly resolved is able to improve the intensity of the simulated rainfalls but not their localization. However, the same simulation initialized with a slightly modified potential vorticity anomaly leads to a more realistic representation of the precipitation both in terms of intensity and localization.

In this situation, many other factors, such as topography or sea influence (Tripoli et al., 2005; Moore et al., 2005) interplay in a complex way and also need to be examined in order to complete this study. We plan to further use the potential vorticity inversion tool to perform short-range ensemble experiments in which the quality of both initial states and model output will be objectively assessed using the so-called model-to-satellite approach (Söhne et al., 2006).

Acknowledgements. This study has been supported by the CNRS/INSU PATOM (Programme Atmosphère et Océan à Multiéchelles). Computational resources were provided by IDRIS (under project 050569-CP1).

Edited by: V. Kotroni and K. Lagouvardos

Reviewed by: anonymous referee 


\section{References}

Chaigne, E. and Arbogast, P.: Multiple potential vorticity inversions in two FASTEX cyclones, Q. J. R. Meteorol. Soc., 126, 17111734, 2000.

Delrieu, G., Ducrocq, V., Gaume, E., Nicol, J., Payrastre, O., Yates, E., Kirstetter, P.-E., Andrieu, H., Ayral, P.-A., Bouvier, C., Creutin, J.-D., Livet, M., Anquetin, S., Lang, M., Neppel, L., Obled, C., Parent-du-Châtelet, J., Saulnier, G.-M., Walpersdorf, A., and Wobrock, W.: The catastrophic flash-flood event of 8-9 September 2002 in the Gard region, France: a first case study for the Cévennes-Vivarais Mediterranean hydrometeorological observatory, J. Hydrometeorol., 6, 34-52, 2005.

Lafore, J.-P., Stein, J., Bougeault, P., Ducrocq, V., Duron, J., Fisher, C., Héreil, P., Mascart, P., Masson, V., Pinty, J.-P., Redelsperger, J.-L., Richard, E., and Vila-Guerau de Arellano, J.: The Meso$\mathrm{NH}$ atmospheric simulation system. Part I: adiabatic formulation and control simulations, J. Atmos. Sci., 32, 320-330, 1998.
Moore, S. A., Wilson, C., and Bell, S.: High resolution modelling of the extreme precipitation event over Algiers in November 2001, Adv. Geosci., 2, 139-143, 2005.

Tripoli, G. J., Medaglia, C. M., Dietrich, S., Mugnai, A., Panegrossi, G., Pinori, S., and Smith, E. A.: The 9-10 November 2001 Algerian flood, Bull. Amer. Meteorol. Soc., 86, 12291235, 2005.

Söhne, N., Chaboureau, J. -P., Argence, S., Lambert, D., and Richard, E.: Objective evaluation of mesoscale simulations of the Algiers 2001 flash flood by the model-to-satellite approach, Adv. Geosci., in press, 2006. 